\title{
Developing a monitoring and verification plan with reference to the Australian Otway $\mathrm{CO}_{2}$ pilot project
}

\author{
KEVIN DODDS, BP \\ Tom Daley and B. FreIFELD, Lawrence Berkeley National Laboratory \\ MILOVAN UroseVIC and Anton KePIC, Curtin University and CO2CRC \\ SANDEEP SHARMA, Schlumberger and CO2CRC
}

$\mathrm{T}$ he Australian Cooperative Research Centre for Greenhouse Gas Technologies (CO2CRC) is currently injecting 100,000 tons of $\mathrm{CO}_{2}$ in a large-scale test of storage technology in a pilot project in southeastern Australia called the CO2CRC Otway Project. The Otway Basin, with its natural $\mathrm{CO}_{2}$ accumulations and many depleted gas fields, offers an appropriate site for such a pilot project. An $80 \%$ $\mathrm{CO}_{2}$ stream is produced from a well (Buttress) near the depleted gas reservoir (Naylor) used for storage (Figure 1). The goal of this project is to demonstrate that $\mathrm{CO}_{2}$ can be safely transported, stored underground, and its behavior tracked and monitored. The monitoring and verification framework has been developed to monitor for the presence and behavior of $\mathrm{CO}_{2}$ in the subsurface reservoir, near surface, and atmosphere. This monitoring framework addresses areas, identified by a rigorous risk assessment, to verify conformance to clearly identifiable performance criteria. These criteria have been agreed with the regulatory authorities to manage the project through all phases addressing responsibilities, liabilities, and to assure the public of safe storage.

Many aspects of the proposed monitoring will be discussed in this overview of the plan. An extensive range of established direct and remote-sensing technologies deployed on the surface and in the borehole are being used for repeat assessments from a reservoir, containment, wellbore integrity, near-surface, and atmospheric perspective. These involve seismic, microseismic, petrophysical well logs, and geochemical

sampling including tracer and isotope analysis, plus associated forward modeling. The naturally occurring $\mathrm{CO}_{2}$ makes it difficult to identify injected $\mathrm{CO}_{2}$. A regional survey of the distribution, type, and origin of existing $\mathrm{CO}_{2}$ will be carried out through soil gas sampling. The areal consequences of $\mathrm{CO}_{2}$ migration and trapping are being addressed through characterization of the hydrodynamic properties of the region. The connectivity and fluid-migration time scales of the potential fresh-water reservoirs are being established using all available (and appropriate) well pressure and geological information. The Otway project has been selected as one of the Carbon Sequestration Leadership Forum (CSLF) projects which reflects its global standing.

\section{Background}

The commercial oil and gas leases (tenements) selected for the project are in an undeveloped $\mathrm{CO}_{2}$ field (Buttress), which is the source of $\mathrm{CO}_{2}$, and a depleted gas field (Naylor), which is the injection/containment site. The extracted and separated $\mathrm{CO}_{2}$ stream is transported by pipeline and injected into a new well (CRC-1), drilled downdip of the existing well, into the depleted Waare reservoir in Naylor Field at a depth of approximately $2000 \mathrm{~m}$. The existing shut-in production well (Naylor-1) is the monitoring well. Characterization of the site has involved the collection of geological, geophysical, and other regionally relevant data and construction of static and dynamic reservoir models. An excellent porous and perme-

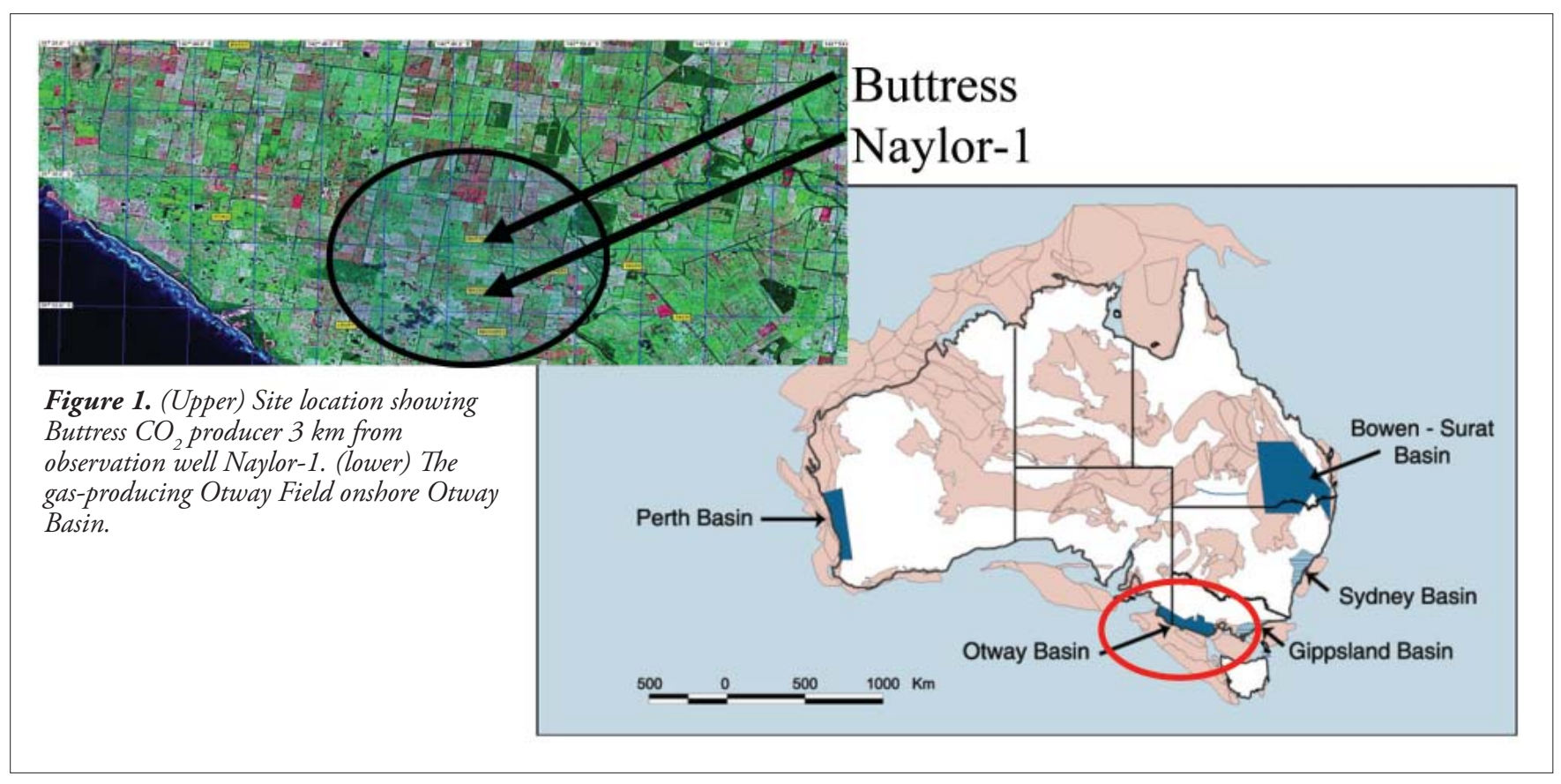




\section{UNCONVENTIONAL RESOURCES AND $\mathrm{CO}_{2}$ MONITORING}

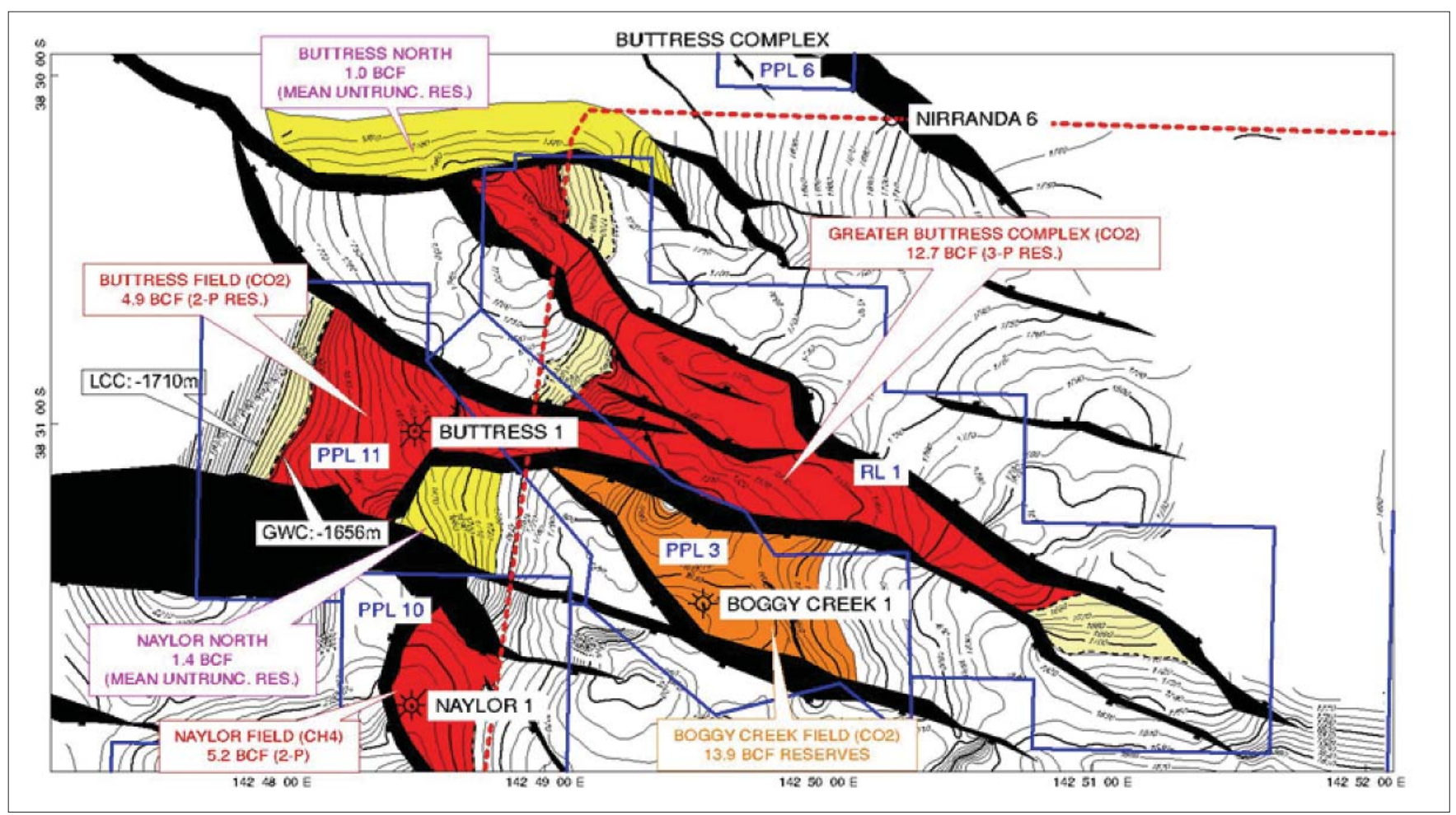

Figure 2. Top Waare sand structure. This compartmentalized field provides a nearly pure $\mathrm{CO}_{2}$ source within 2-3 km of Naylor-1, a former gas producer that became the monitoring well.

able geological formation provides a highly suitable reservoir system for $\mathrm{CO}_{2}$ storage. In summary, the site assessment, indicating that the Waare Formation is suitable for $\mathrm{CO}_{2}$ storage, concluded there are no significant faults evident in the wells at the Waare C level and there is a fairly uniform thickness. The local and regional seals have contained a number of natural $\mathrm{CO}_{2}$ accumulations in the eastern Otway Basin over geological time. The storage reservoir has enough porosity and permeability to accept the injected $\mathrm{CO}_{2}$ at the rates forecast. The injected $\mathrm{CO}_{2}$ is predicted to move updip from the injector, migrate to the crest of the fault block, and accumulate below the residual methane gas cap in the vicinity of Naylor-1 (Figure 2).

\section{Pilot project risk assessment}

A comprehensive risk assessment was undertaken before $\mathrm{CO}_{2}$ injection. A systematic approach has been taken that considers both engineered and natural systems. The former consist of the wells, the plant, and the gathering line. The latter includes the geology, the reservoir, the overlying and underlying formations, and the groundwater flow regimes. The qualitative risk assessment created a list of potential risks, their specific issues, and potential consequences. Mitigation measures were then defined to lower the risk to acceptable levels. This was supplemented by a quantitative risk assessment (QRA) where probabilities assessed through Monte Carlo simulation were assigned to specific risk events and simulations run to consider the range of impacts.

The qualitative assessment is developed through a "risk register" designed to cover all aspects: initial planning and pre-implementation, production, processing, transportation, drilling, and injection risks, as well as personnel and decom- missioning risks. Extensive geoscience work suggested that the source and sink meet project demands with high certainty. The area is not new to petroleum-type activities; several production wells, a gas injection and storage site, and processing plants in the immediate vicinity have been working safely for years and are accepted by the local community. Long-term containment needs were assessed through evaluation of the potential natural and man-made leakage pathways, their likelihood of being activated, and an assessment of the amount and duration of any leaked volumes. Natural pathways include permeable zones in the seal, faults either existing or caused by regional overpressurization or earthquakes. Incorrect mapping of the migration direction and exceeding the spill point can allow the $\mathrm{CO}_{2}$ to migrate beyond its intended area. This risk is minimal as Naylor is a depleted oil/gas field which has previously held more fluids than are being injected and probably for many millions of years. There are also multiple barriers between the storage reservoir and shallow aquifers.

The QRA follows the RISQUE method (Bowden et al., 2004), which uses a formal group of experts whose quantitative judgments are incorporated into a risk analysis and management framework. The basic approach is to characterize and quantify risk both in terms of likelihood of identified risk events and consequences. The expert panel assesses all available information against a list of containment risk issues. This list is used consistently at different sites and, hence, provides a means to quantitatively compare different sites for containment risk. Overall, the risk analysis demonstrated that the project area has low risk events with minimal consequences. The planned monitoring addressed risks by monitoring at the wells, for the potential of overpressurization and by monitoring for the plume migration pathway. 


\section{Monitoring and verification role}

The goals of a monitoring framework are to provide comprehensive information from direct measurements and remote sensing of the injection and storage of $\mathrm{CO}_{2}$, such that we can appropriately document the complete storage process (the safe transport, injection, containment of $\mathrm{CO}_{2}$, and the subsequent safe abandonment and restoration of the site). We must meet the requirements of the Regulatory Impact Statement 2004 from the Commonwealth Organization of Australian Governments that, for monitoring and verification, a regulatory framework should:

- Provide for the generation of clear, comprehensive, timely, and accurate information that is used to effectively and responsibly manage environmental, health, safety, and economic risks and to ensure that set performance standards are being met.

- Determine to an appropriate level of accuracy the quantity, composition, and location of gas captured, transported, injected, and stored and the net abatement of emissions. This should include identification and accounting of fugitive emissions.

The monitoring technologies comprise diverse methods and measurement systems crossing many disciplinary boundaries. We categorized them by their means of measurement (either remote or direct sampling) or by their domain of operation:

- The subsurface domain to monitor and verify the deep injection and migration behavior of injected $\mathrm{CO}_{2}$, from the surface or borehole.

- The near-surface domain comprising sampling and remote measurements to verify the nonseepage to shallow zones and soils again from surface and borehole.

- The atmospheric domain, comprising a baseline characterization of seasonal and diurnal variation of gas distribution and composition accumulated over suitable time which can be monitored by point-source gas sampling, coupled with dispersion modeling or by spectral absorption and infrared detectors locally or by aircraft and satellite.

The monitoring technologies are deployed in a number of modes during the project's lifetime. Monitoring can be categorized into baseline and operational monitoring. Verification monitoring consists of both subsurface and environmental confirmation of performance criteria (Figure 3).

\section{Pilot project phasing and regulatory performance} indicators

The project has been divided into four phases that reflect the focus on storage and related monitoring activities. Completion of each phase is assessed by verification of performance against objectives:

- Phase 1A pre-injection (establish injection and migration models and uncertainties; establish the baseline measurements database)

- Phase $1 \mathrm{~B}$ production and injection (environmental impact within regulatory bounds; injection/migration within bounds predicted by model)

- Phase 2 postinjection (verify stable plume within model prediction; appropriate decommissioning certificate(s); wells decommissioned and sites restored)

- Phase 3 postclosure (no evidence of injected $\mathrm{CO}_{2}$ within specified period)

- Phase 4 longer term (no evidence of injected $\mathrm{CO}_{2}$ within specified period)

Phases $1 \mathrm{~A}, 1 \mathrm{~B}$, and 2 will require a continuum of highintensity monitoring. The transition from one phase to another will depend on well-defined engineering determinants. Phase 2 will see postinjection closure (or sale) of the $\mathrm{CO}_{2}$ production Buttress well and decommissioning of the surface facilities. Monitoring will be ongoing in the Naylor site to validate the transition criteria to Phase 3 . The validation that the plume is now stable will come from log-based measurements showing no evidence of $\mathrm{CO}_{2}$ in the overlying formation beyond secondary containment. In addition, fluid samples from four existing deepwater wells should show no evidence of the injected $\mathrm{CO}_{2}$. Soil and air samples from the proximity of the monitoring well (Naylor-1) and the injector (CRC-1) wells also must show no evidence of the injected $\mathrm{CO}_{2}$. Phase 3, focused on public assurance and monitoring for long-term storage security, will augment an existing program by the local water authority with testing of soil samples near the existing water wells for evidence of injected $\mathrm{CO}_{2}$. If no evidence of the injected $\mathrm{CO}_{2}$ is detected in two years, this 


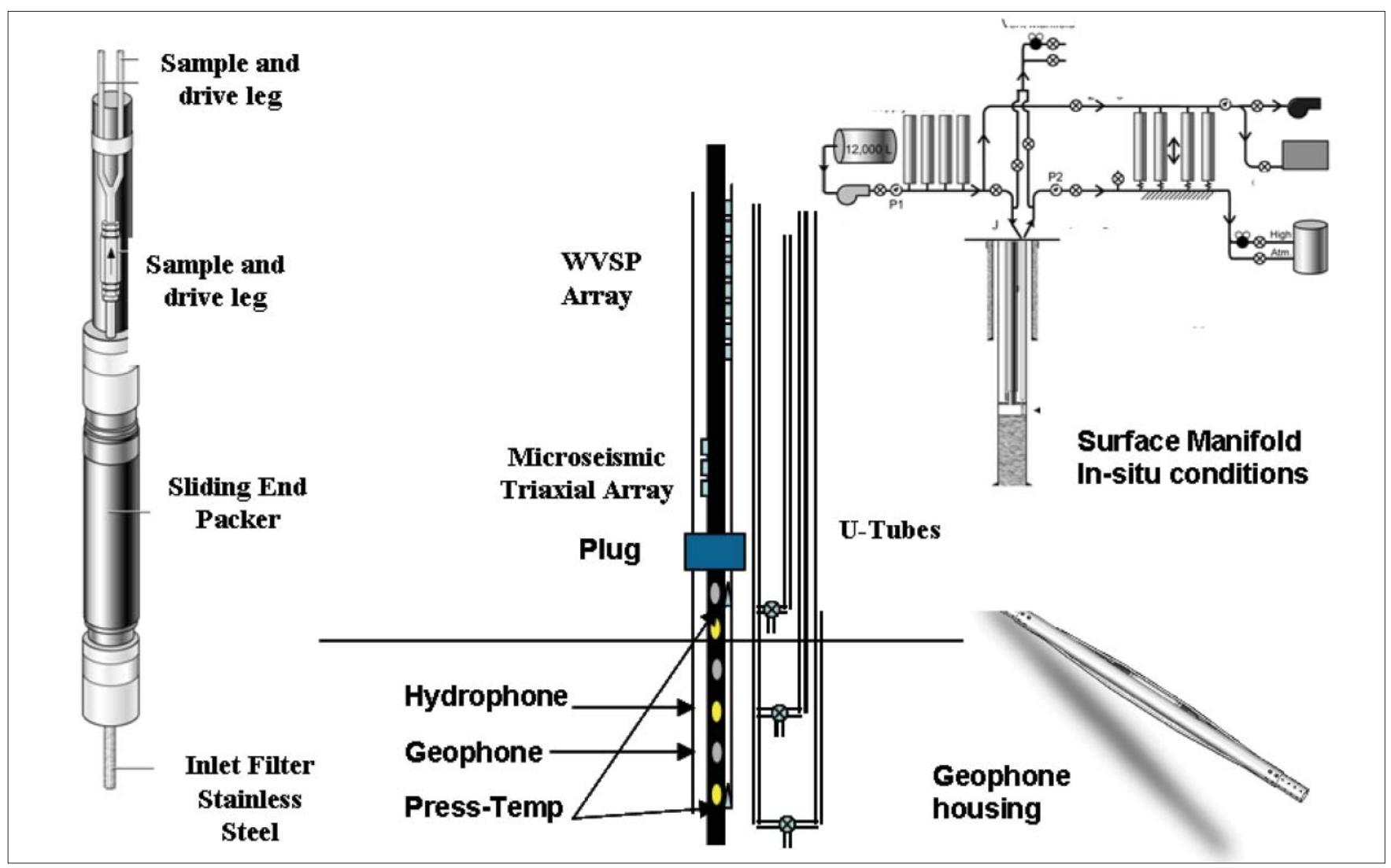

Figure 4. Integrated seismic and geochemical completion showing u-tube downhole sampling, surface manifold, and the integrated completion with u-tubes, seismic, and other sensors. The horizontal line represents the methane-water interface prior to injection.

phase can transition into Phase 4. Monitoring for Phase 4 will continue to focus on public assurance through the augmented testing program in the deep wells. Again, where there is no evidence of injected $\mathrm{CO}_{2}$ for a further two years, this phase can terminate. These time scales are pertinent for this project and may be longer for large-scale storage projects. The project is currently at the beginning of Phase $1 \mathrm{~B}$. The injected $\mathrm{CO}_{2}$ is magmatic in origin and consequently has a quite different isotopic signature than $\mathrm{CO}_{2}$ generated biologically and from fossil fuels and, hence, can be discriminated.

\section{Otway subsurface monitoring}

The first task was to refine the uncertainties in reservoir properties. There has been a reasonable elapsed time between the original acquisition of $3 \mathrm{D}$ seismic and the subsequent production and shut-in of well Naylor-1. There is residual gas within the Naylor reservoir with uncertainty as to the gaswater contact. The residual gas significantly challenges direct detection of the $\mathrm{CO}_{2}$ plume by seismic once it migrates out of the injection well's water zone. More precise understanding of these properties will determine the monitoring options. Consequently, Naylor-1 was re-entered to establish gas-water contacts with reference to a reservoir saturation log and the integrity of the cement bonds through casing and cement inspection logs. This provided the opportunity to test the viability of VSP methods. A new injection well (CRC-1) was drilled within $300 \mathrm{~m}$ of the monitoring well (Naylor-1). Data gathering includes extensive coring above and through the top seal and reservoir. Openhole wireline logs, pressure measurements, and fluid samples from the reservoir have also been taken. Pressure transient testing determined the hydrogeologic characteristics prior to injection of $\mathrm{CO}_{2}$. The results have been used to modify the injection protocol. Cement inspection logs have evaluated the integrity of the cement bonding. Downhole pressure and temperature gauges have monitored injection conditions. Seismic monitoring is in three distinct phases: prior to injection to establish baseline data; during injection (i.e., between injection and breakthrough); and postinjection for comparison against the baseline data (3D surface seismic and 3D VSP). In collaboration with CO2CRC, Lawrence Berkeley National Laboratories designed and built an integrated instrument, installed in Naylor-1 in 2007 (Figure 4), to obtain geochemical and seismic data during the injection period (Kepic et al., 2007).

This completion provides geochemical sampling at three distinct levels, in combination with three types of geophysical monitoring activities. The geochemical sampling occurs through three sets of "u-tubes" with inlets above and below the gas contact. There are also two sets of pressure and temperature sensors in these locations. The sampling occurs through one-way valves, and the fluids (retaining reservoir conditions) are lifted by nitrogen to the surface. The first seismic activity is an array of geophones about $500 \mathrm{~m}$ above the reservoir to walkaway data during injection The second is three triaxial geophones within $300 \mathrm{~m}$ above the reservoir to monitor any microseismic events which signal changes in stress state as- 
sociated with the injection and detect or rule out any signs of reactivation of the bounding fault. The third consists of hydrophones and geophones within the reservoir to look at high-resolution traveltimes and changes associated with the changing fluid level at the monitoring well. The whole assembly, together with surface pressure control, was successfully assembled and lowered over a 10-day period in quite adverse weather in October 2007 (Figure 5).

\section{Preliminary VSP acquisition}

Surface and borehole seismic are important survey tools, as the geological formations and structures can be defined, and quite subtle changes associated with the presence of the supercritical fluid can be detected. We have forward modeled the expected seismic response ( $\mathrm{Li}$ et al., 2006) and predicted the traveltime differences associated with the $\mathrm{CO}_{2}$ plume with the gas, well below the detectability of conventional acquisition. We have studied in the laboratory the elastic response of the reservoir under different effective stresses and for sub- and supercritical $\mathrm{CO}_{2}$ together with methane in comparison to Gassmann prediction (Siggins, 2006). Prior to acquiring the 3D VSP, we calibrated the performance of borehole data via walkaway VSPs with multicomponent surface lines to tie back to the existing $3 \mathrm{D}$ seismic. The VSPs have provided higher-

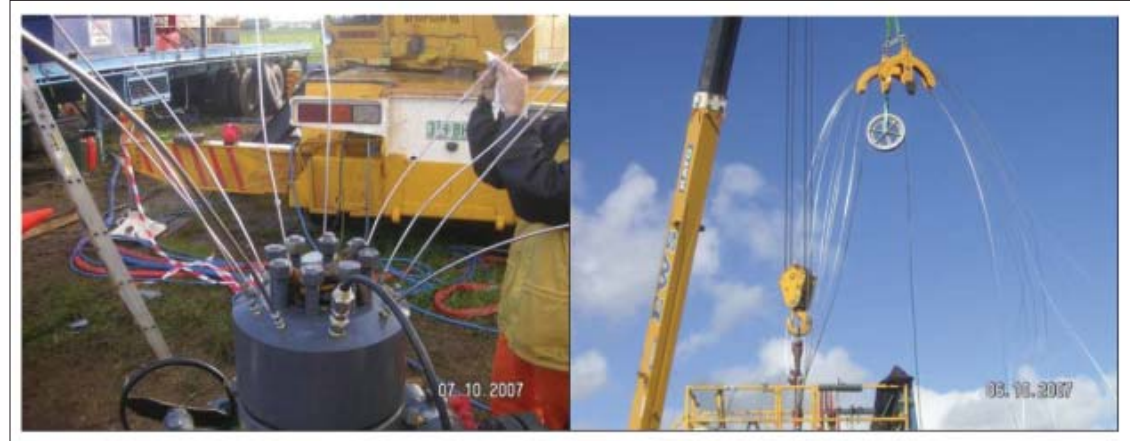

Figure 5. Assembling and deployment of the complete system was a complex and successful operation. These figures show the wellhead with flow tubes and cable connections (left) and control of the u-tubes while inserting the integrated assembly (right).

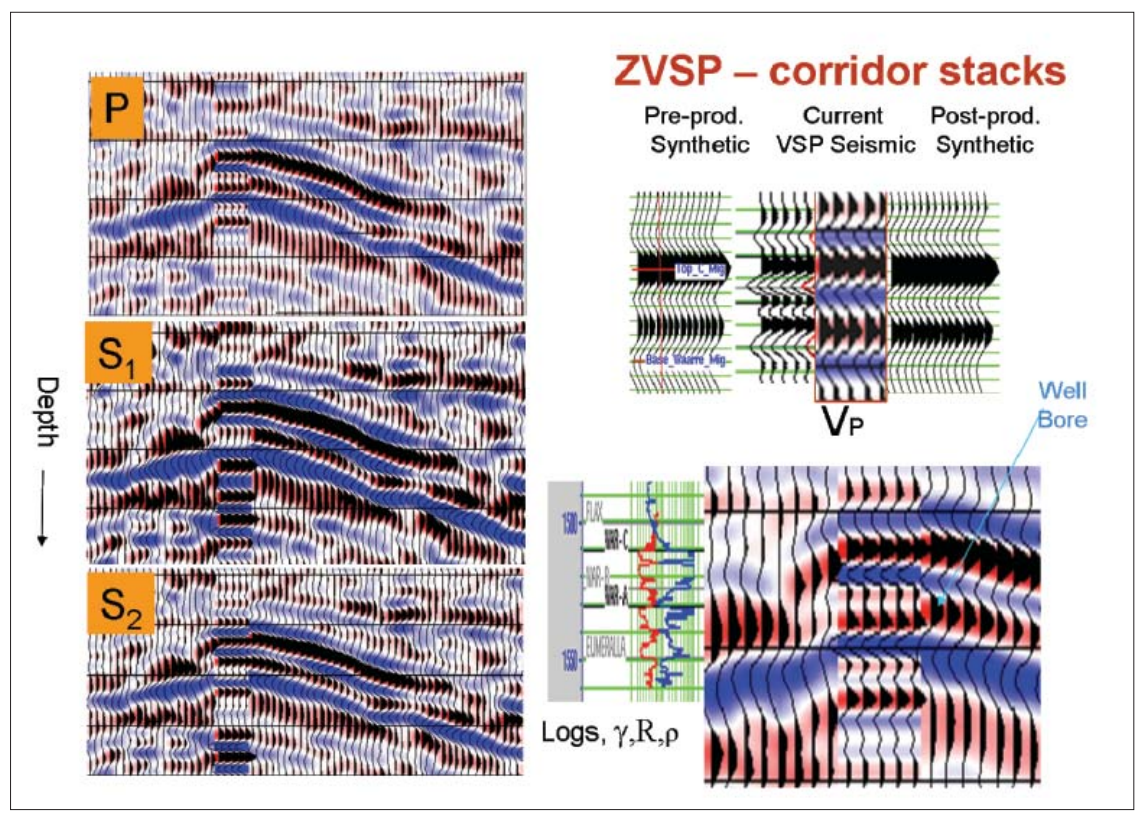

Figure 6. Surface seismic with inserted compressional and shear VSP stacks.

resolution imaging (bandwidth up to 140

$\mathrm{Hz}$ at target) and in particular help infer fluid properties from elastic AVO data. Corridor sections of the VSP traces, surface seismic response, and synthetics show the resolution compared to the surface seismic (Figure 6). We were also able to extract very valuable shear information from the VSPs, which is also displayed on the left with the compressional response (Urosevic et al., 2007).

Downhole fluid sampling at the monitoring well through the integrated system's geochemical u-tubes is being carried out before, during, and after $\mathrm{CO}_{2}$ injection. Chemical and isotopic analysis is being carried out on both fluids and gases. The changes in the elemental and isotopic compositions are being used to monitor the geochemical reactions in the reservoir to establish the nature and amount of geochemical trapping of $\mathrm{CO}_{2}$ (Perkins et al., 2006). Tracers (both injected and natural) confirm the arrival of the $\mathrm{CO}_{2}$ plume at the monitoring well. In addition, their relative retardation determines saturations in the region swept by the $\mathrm{CO}_{2}$ plume, thereby showing the extent of gravity override versus uniform volumetric sweep. Tracers inserted in the injected $\mathrm{CO}_{2}$ stream will be significant in detecting movement beyond and through the seal, into overlying aquifers, soil leakage, and atmosphere. It is expected that each tracer will uniquely partition between the aqueous and supercritical $\mathrm{CO}_{2}$ phases. If the partitioning between the phases is appropriate, the tracer may act as a precursor to the injection stream and provide an early signal of movement. A number of chemical tracers are being evaluated for injection in the supercritical carbon dioxide stream.

The naturally occurring subsurface $\mathrm{CO}_{2}$ makes identifying the injected $\mathrm{CO}_{2}$ more complex. A regional survey of the distribution, type, and origin of existing $\mathrm{CO}_{2}$ is being carried out through sampling of soil gas, hydrogeology, water chemistry, and atmospheric measurements. Sampling over a defined grid is repeated several times per year (to account for seasonal effects) — before, during, and after injection. The consequences of $\mathrm{CO}_{2}$ migration and trapping are being addressed through characterization of the region's hydrodynamic properties. The connectivity and fluid migration timescales of the existing fresh-water reservoirs are established using available hydraulic head, well pressure, and geological information. This provides input into establishing fluid pathways, flow timescales, and identifying flow barriers due to facies changes 


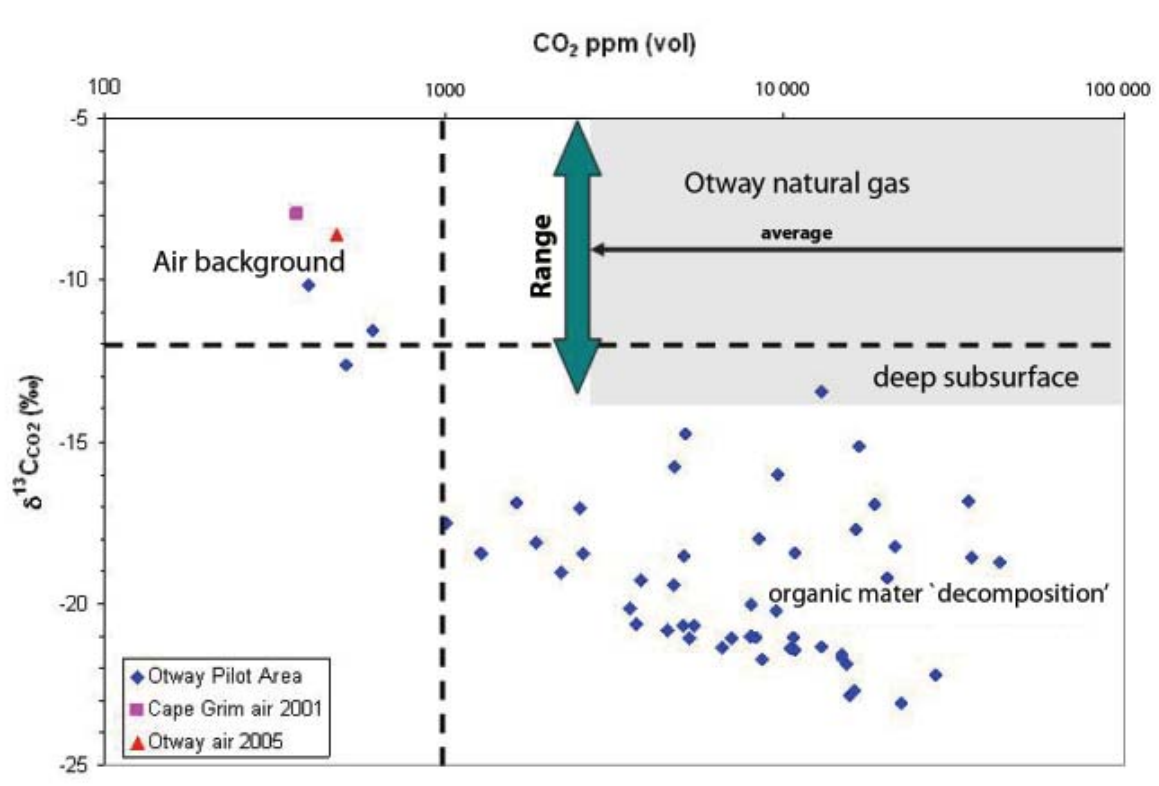

Figure 7. Soil sampling showing predominant biological signature.

and faults. Atmospheric monitoring equipment provides the environmental background against which anomalous sources of $\mathrm{CO}_{2}$ can be detected. The proposed location and layout in the Otway Project has some significant advantages for atmospheric monitoring. It is in a rural region with the coast only $4 \mathrm{~km}$ to the southwest. SW winds are prevalent. The short fetch across mainly pasture or lightly forested land will minimize the variations in $\mathrm{CO}_{2}$ concentration resulting from ecological exchange. The $\mathrm{CO}_{2}$ source well (Buttress), and other sources of $\mathrm{CO}_{2}$, and their associated infrastructure, which may release $\mathrm{CO}_{2}$ and other gases, are downwind of the proposed geosequestration well when SW winds prevail. The Cape Grim Baseline Atmospheric Pollution Station (a WMO Global Atmosphere Watch station, operated jointly by CSIRO and the Bureau of Meteorology) has monitored atmospheric composition for decades, and their data can be a baseline reference. $\mathrm{A} \mathrm{CO}_{2}$ analyzer system LoFlo (Francey et al., 2003), which makes high-precision continuous $\mathrm{CO}_{2}$ measurements, provides the data stream from Cape Grim which will be compared with a similar system at Otway. The origin of observed $\mathrm{CO}_{2}$ can be determined through atmospheric dispersion analysis (Hurley et al., 2005). The strategy consists of measurements of $\mathrm{CO}_{2}$ and tracer gas concentrations up- and downwind of the source plus an understanding of the dispersion from small scales (tens to hundreds of meters, influenced by micrometeorology) to larger scales (several kilometers, influenced additionally by mesoscale and synoptic winds). The $\mathrm{CO}_{2}$ is of magmatic origin and can be distinguished by its enriched 13C isotopic content (Figure 7) compared to that derived from ecological exchange, biomass burning and fossil fuel (Watson et al., 2008).

\section{Establishing repeatability for time-lapse seismic (4D)}

We established a test sequence to benchmark the performance of sources for both VSP and surface seismic: a minivibrator and a hydraulic weight drop mountable onto a lo- cally hired "Bobcat." Initial comparison (Figure 8) of 2007 weight-drop data with 2006 minivibrator data along the same line and occupying the same positions showed a 12- $\mathrm{dB}$ decrease in energy (Urosevic et al., 2007).

Since a previous comparison in Western Australia showed very little difference in frequency response and energy, we immediately concluded that nearsurface conditions were responsible. The 2006 data were acquired after a normal wet season and the 2007 data after a prolonged drought (in fact, the water table had dropped several meters). We retested the line using the minivibrator and nearly identical results confirmed the change in the water table change was the culprit (Figure 9). The operational consequences of this trial were substantial: We postponed the 3D survey to when conditions were comparable to the 2006 survey (when soaking rain provided better coupling of the source signal to the subsurface). An important outcome was to document the influence of the near surface on the data repeatability.

\section{Conclusion}

The CO2CRC Otway Project is comprehensively testing all phases of large-scale $\mathrm{CO}_{2}$ geosequestration, including nearterm and long-term monitoring issues. This monitoring confirms objectives necessary to transition from phase to phase. The monitoring uses established technology, but an innovative integrated geochemical and geophysical completion for the monitoring well has also been developed. Management of the quality of the time-lapse data has been achieved by thorough pretesting for repeatability factors. The testing program has shown that the repeatability of subsequent surveys as well as bandwidth critically depend on repeating the near-surface environmental conditions of water saturation.

Injection started April 2008, and approximately 50,000 tons had been injected by May 2009. A baseline seismic survey in January 2008 consisted of a 3D surface seismic and a 3D VSP. A repeat 3D surface seismic was carried out in January 2009. Several high-resolution transit time surveys have been carried out and are being processed for time-lapse evaluation. A repeat 3D VSP will be acquired after cessation of injection sometime in 2009. Currently, observations are being made for the arrival of a number of tracers which were co-injected in January 2009.

Suggested reading. "Assessing risk in $\mathrm{CO}_{2}$ storage Projects" by Bowden and Rigg (The APPEA Journal, 2004). "Measuring atmospheric carbon dioxide- the calibration challenge" by Francey and Steele (Accreditation and Quality Assurance, 2003). "TAPM: A practical approach to prognostic meteorological and air pollution modeling" by Hurley et al. (Environmental Modelling and Software, 2005). "Integrated geochemical and geophysical com- 


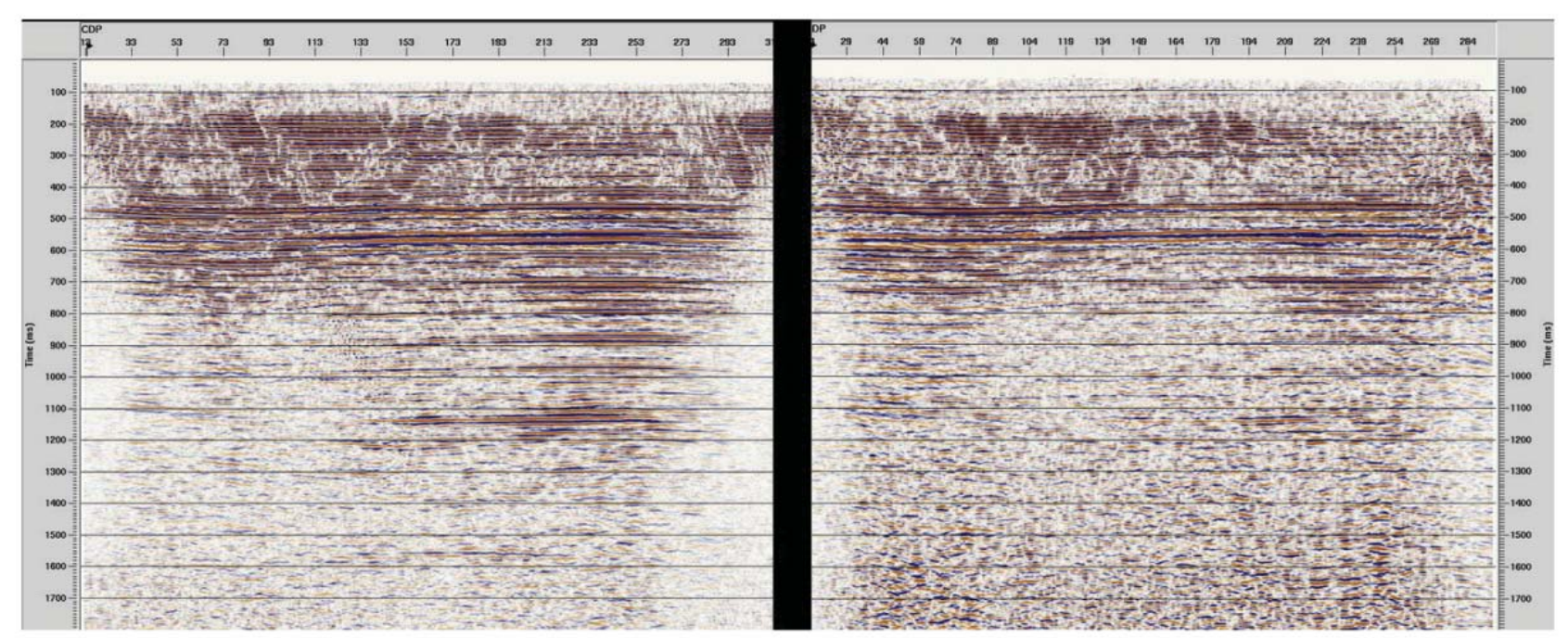

Figure 8. Comparison of 2006 minivibrator source (wet) with 2007 weight-drop data (dry).

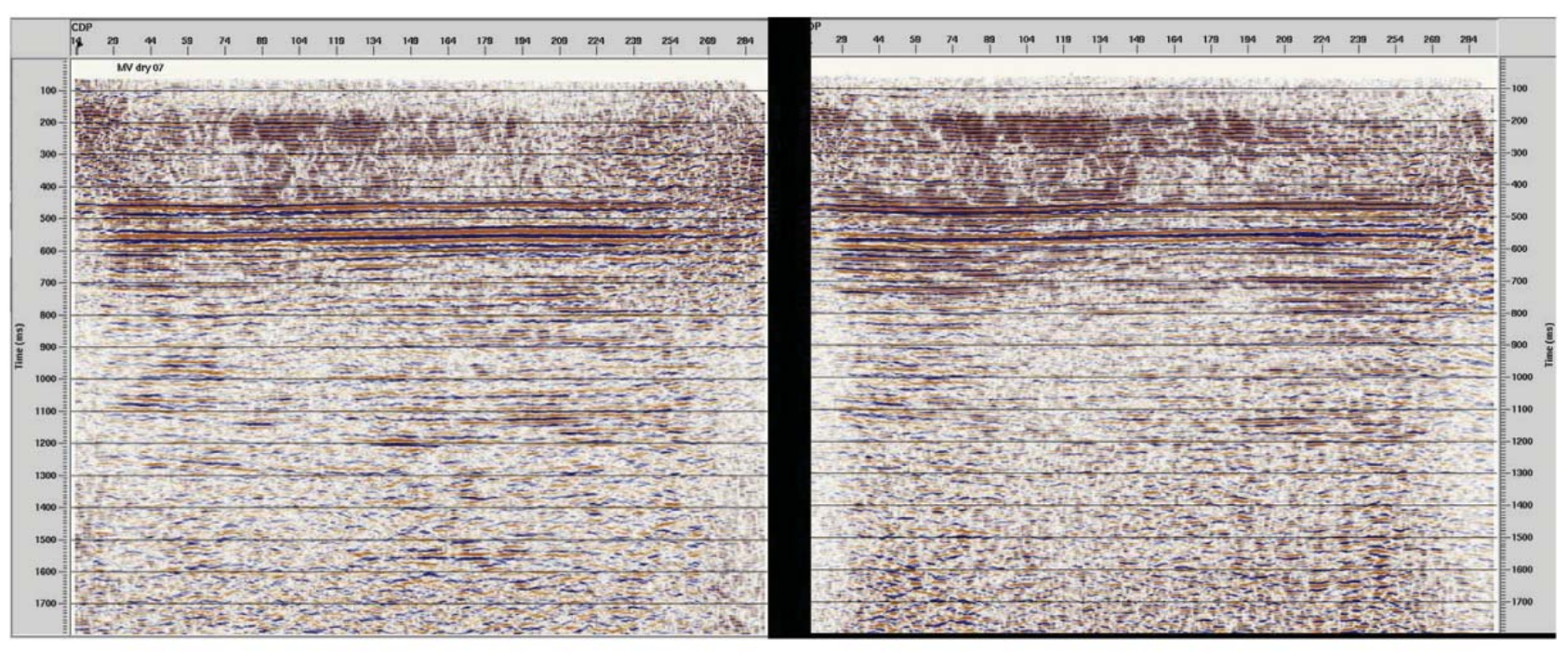

Figure 9. Comparison of 2007 minivibrator source (dry) with 2007 weight drop data (dry).

pletion for Naylor-1" by Kepic et al. (CO2CRC Symposium, 2007). "A rock physics simulator and its application for $\mathrm{CO}_{2}$ sequestration" by Li et al. (Exploration Geophysics, Butsuri-Tansa, and Mulli-Tamsa, joint special issue Geophysics of Geosequestration, 2006). "The coupling of geochemical modelling, fluid monitoring and tracer injection programs to optimize a monitoring program at the Otway Basin $\mathrm{CO}_{2}$ storage pilot" by Perkins et al. (GHGT-8 Proceedings, 2006). "Velocity-effective stress response of $\mathrm{CO}_{2}$ saturated sandstones" by Siggins (Exploration Geophysics, Butsuri-Tansa, and Mulli-Tamsa, joint special issue Geophysics of Geosequestration, 2006). "Geophysical imaging for $\mathrm{CO}_{2}$ monitoring of Otway time lapse VSP program” by Urosevic et al. (ASEG Conference, 2007a). "Land seismic acquisition repeatability for time-lapse monitoring of $\mathrm{CO}_{2}$ sequestration" by Urosevic et al. (ASEG Conference, 2007b). Soil Gas Baseline Characterisation Study-Methodology and Summary by Watson and Boreham (CO2CRC Report, in preparation). TEE
Acknowledgments: This paper depends substantially on all the contributions from the CO2CRC team; Don Sherlock, Allison Hennig, Jim Underschultz, Linda Stalker, David Etheridge, Ray Leuning, Tony Siggins and Kevin Dodds of CSIRO, Milovan Urosevic, and Anton Kepic from Curtin University, Max Watson and Peter Van Ruth from University of Adelaide, Ernie Perkins seconded from the ARC, Canada. Tom Daley and Barry Friefeld, LBNL and Otway project manager Sandeep Sharma (seconded from Schlumberger). Dodds was responsible for the $M \circlearrowleft V$ program for CO2CRC while based in CSIRO, he has subsequently taken a position in BP Alternative Energy.

This paper originally appeared in the ${ }^{\circ} 2008$ Offshore Technology Conference published presentations and is reprinted with permission.

Corresponding author: ssharma@co2crc.com.au 